\title{
A Foundation for the Conception of Law as Practical Reason
}

\section{Introduction}

Ever since H. L. A. Hart's powerful criticism of the "gunman model" of law-on which law is understood as a set of commands backed by sanctions or by the threat of harm-it has become increasingly standard in legal philosophy to accept that some form of conceptually necessary relation obtains between law and practical reason. On this approach, law is conceived as a normative system meant to provide practical guidance, with the result that legal norms figure in some essential way into our reasons for action. It has been argued on this basis that law is inseparable from practical reason in the specific sense of being a particular instantiation, or species, of it. In this essay I will refer to this claim as the "conception of law as practical reason".

Figuring prominently among those who have defended the conception of law as practical reason is Robert Alexy. ${ }^{1}$ Alexy has developed a comprehensive conception of law as practical reason of nonpositivist flavour that is deeply affected, and indeed justified, by his own theory of practical reason, which on this basis should be regarded as fundamental to his legal philosophy. ${ }^{2}$ This understanding of Alexy's theoretical project justifies my choice to provide a detailed reconstruction of his view of practical reason (Section 3). Such view draws importantly on the Kantian tradition of practical philosophy and supports a conception of law not just as simply connected to practical reason but as an institutionalization of it. With this reconstruction in place I pass, in Section 4, to critically engage with Alexy's foundation of practical reason shaped by a weak transcendental-pragmatic argument, which in its present form, I will claim, can only show why sometimes we ought to follow the guidance of practical reason, and which consequently makes the authority of practical reason ultimately dependent on individual decision. This in turn makes practical reason a contingent notion, and less

\footnotetext{
${ }^{1}$ The work of Alexy has significantly contributed to set the legal-philosophical agenda in continental Europe since the publication of his $A$ Theory of Rational Argumentation in 1978. In addition, especially as a result of the translations of his main works in English (see Robert Alexy, A Theory of Constitutional Rights (Oxford: Oxford University Press, 2002; or. ed. 1986) and Robert Alexy, The Argument from Injustice (Oxford: Clarendon, 2002; or. ed. 1992), Alexy's legal philosophy has recently found its way into the Anglo-American debate too, where previously it was insufficiently discussed. See, for instance, the essays contained in George Pavlakos (ed.) Law, Rights and Discourse: the Legal Philosophy of Robert Alexy (Oxford: Hart, 2007) and Matthias Klatt (ed.), Institutionalized Reason: The Jurisprudence of Robert Alexy (Oxford: Oxford University, 2012).

${ }^{2}$ This conception emerges most clearly in Robert Alexy, A Theory of Legal Argumentation (Oxford: Clarendon, 1989; or. ed. 1978), Robert Alexy, "My Philosophy of Law: The Institutionalisation of Reason", in L. J. Wintgens (ed.), The Law in Philosophical Perspective (Dordrecht: Kluwer, 1999), pp. 23-45, Robert Alexy, "The Special Case Thesis", Ratio Juris 12 (1999): pp. 374-84, Robert Alexy, A Theory of Constitutional Rights (Oxford: Oxford University Press, 2002; or. ed. 1986), and Robert Alexy, The Argument from Injustice (Oxford: Clarendon, 2002; or. ed. 1992).
} 
attractive for it from a Kantian perspective. Yet we can avoid that outcome - and still preserve Alexy's comprehensive conception of law as practical reason-by strengthening his foundational argument. This is something I intend to do in Section 5, where, by building on the idea of constitutive necessity I put forward a transcendental foundation of practical reason, thereby resting the conception of law as practical reason on a noncontingent basis.

This essay is therefore to be understood as primarily a discussion of one particular version of the conception of law as practical reason: its specific focus is provided by Alexy's treatment of practical reason and law. But my ultimate concern here is with the foundation of a whole tradition of legal philosophy-the conception of law as practical reason, especially in its Kantian variant - and not just with one theory of law in that Alexy's account will be assessed by its ability to legitimise the appeal to practical reason to interpret, and make sense of, law as a system for guiding and justifying conduct. Thus, in the perspective endorsed in this study, the analysis and evaluation of Alexy's conception of law as practical reason are to be considered part and parcel of a broader attempt to subject the foundation of the conception of law as practical reason to critical scrutiny by so arriving at a critical assessment of that conception in general. This perspective of analysis justifies the decision to introduce the main argument deployed in this essay with a concise presentation of the wider tradition of legal thought - the conception of law as practical reason — which Alexy's theory of law is a specific instance of and contribution to. The introduction to the conception of law as practical reason, which is offered in Section 2, is then meant to situate Alexy's legal philosophy within the contemporary debate concerning the connection between law and practical reason as well as to clarify the significance of a critical insight into such philosophy.

\section{The Conception of Law as Practical Reason}

The claim that law and practical reason are conceptually connected can be regarded as orthodoxy in contemporary legal philosophy. Those who defend this claim make no suggestion that practical reason alone determines the contents and fundamental features of a legal system, to be sure. They rather argue that law should be conceived as an institution which bears "on practical deliberations by changing an addressee's reasons for action". 3 On this view, law is recognised to have a twofold quality. For one thing, it sets up a coercive system, namely, a system backed by threats of sanctioning deviant conduct; for another thing, it claims the legitimate authority, and not just the power, to govern social relationships. ${ }^{4}$

\footnotetext{
${ }^{3}$ Steven Burton, "Law as Practical Reason" Southern California Law Review 62 (1989): p. 768.

${ }^{4}$ On the twofold quality of law see Gerald Postema, "The Normativity of Law" in R Gavison (ed.), Issues in
} 
Insofar as it is acknowledged to be not just coercive but also authoritative, law is taken to be an institution that "seeks to guide the behaviour of rational beings through rational means". 5 In this law is at one with practical reason: both-law and practical reason-address individuals qua rational deliberators, namely, subjects capable of reasoning about the kind of conduct that should be undertaken in a given context.

The widespread convergence on these claims should not be taken to mean that legal theorists today (even within mainstream jurisprudence) all share the same conception of law as practical reason. Indeed, the conception of law as practical reason can potentially take any number of inflections depending on the way practical reason itself is conceptualized. And the way in which practical reason has been conceptualized in contemporary legal philosophy could not be more plural and internally differentiated. Yet, at the risk of oversimplifying a large body of literature by compression, at a high level of abstraction one can summarize at least the most influential positions within the current debate in terms of a basic distinction: the distinction between modest conceptions and ambitious conceptions of practical reason.

A conception of practical reason is modest, according to the proposed classification, insofar as it defines the capacity for rational deliberation as the capacity, which is quite limited in scope, to single out and organize in a coherent fashion the means for the pursuance of one's practical goals. On this view, by itself practical reason does not set the ends of action, which are given to agents by other faculties, and is concerned merely with the strategies required to pursue those ends. The modest conception finds a paradigmatic statement in instrumentalism, which is the view that the fundamental principle of practical reason-the most elemental one and, in fact, the only one that can be grounded beyond doubt-is the socalled "instrumental principle". ${ }^{6}$ In a nutshell, the instrumental principle, in one of its possible

Contemporary Legal Philosophy (Oxford: Clarendon, 1987), pp. 81-104, Joseph Raz, Ethics in the Public Domain (Oxford, Clarendon, 1994), pp. 195-209, Robert Alexy, The Argument from Injustice (Oxford, Clarendon, 2002), pp. 35-40, Leslie Green, "Law and Obligations" in J Coleman and S Shapiro (eds.), The Oxford Handbook of Jurisprudence and Philosophy of Law (Oxford: Oxford University Press, 2002), pp. 514547, Robert Alexy "On the Concept and the Nature of Law", Ratio Juris 21 (2008): pp. 281-299.

5 Gerald Postema, "The Normativity of Law" in R Gavison (ed.), Issues in Contemporary Legal Philosophy (Oxford: Clarendon, 1987), 91-2. See also Joseph Raz, Engaging Reason (Oxford, Oxford University Press, 1999), p. 67, where it is claimed that legal subjects should be regarded as persons having the "capacity to perceive and understand how things are, and what response is appropriate to them" as well as the "ability to respond appropriately" to situation and inputs. Accordingly, the subjects of law are taken to be able to determine their lives "in accordance with their appreciation of themselves and their environment, and of the reasons with which, given how they are, the world presents them".

${ }^{6}$ Instrumentalism is the default positions of neo-Humeans and rational choice theorists, who have significantly contributed to the debate concerning the concept of law among legal philosophers. Statements of, and arguments for, instrumentalism can be found in James Buchanan, The Limits of Liberty (Chicago: Chicago University Press, 1975), David Gauthier "Reason and Maximization", Canadian Journal of Philosophy 4 (1975), pp. 411-33, David Gauthier, Morals by Agreement (Oxford: Clarendon, 1986), Mitchel Resnik, Choices (Minneapolis: University of Minnesota Press, 1987), pp. 3-20, Donald Hubin, "Irrational Desire", Philosophical Studies 62 
formulations, prescribes the agent to take the means that are necessary to achieve the end(s) she is committed to. Instrumentalism, accordingly, holds that the function of practical reason consists in figuring out what one ought to do in order to achieve one's goals, as those goals are determined by one's inner states such as personal preferences, desires, needs or commitments.

This statement does not mean that practical reason, on a modest conception, is confined to deliberating about the effectiveness of certain means. At least on one variant of modest conception of practical reason - a variant that has profoundly shaped the contemporary debate within legal philosophy_-practical deliberation covers not just considerations about the effectiveness of the means one chooses but also considerations about their mutual consistency, coherence and internal relationships. ${ }^{7}$ Related, practical reason is conceived as the capacity to structure and reorganise the multiple means functional to reaching one's objectives. The (limited) extension of the scope of practical deliberation resulting from the endorsement of this variant of the modest conception has at least two important theoretical implications. On the one hand, it has enabled practical philosophers to recognise the existence of principles of reason that are either overlooked or not acknowledged at all by traditional instrumentalism. ${ }^{8}$ On the other hand, within jurisprudence it has been used to support the positivist planning theory of law. This theory conceives of law as an institution of social planning, meaning that the law is to be regarded as a large-scale, hierarchically structured activity which guides behaviour through the creation, implementation and enforcement of collective plans enabling individuals in a social group to "lower their deliberation, negotiation, and bargaining costs, increase predictability of behaviour, compensate for ignorance and bad character, and provide methods of accountability". 9

(1991), pp. 23-44, Donald Hubin, "What's Special about Humeanism", Nous 33 (1999), pp. 30-45, and Christoph Fehige, "Instrumentalism", in E Millgram, Varieties of Practical Reasoning (Cambridge (Mass.): MIT Press, 2001), pp. 49-76. For a general introduction to the Humean theory of practical reason, see Peter Railton, "Humean Theory of Practical Rationality" in D Copp (ed.), The Oxford Handbook of Ethical Theory (Oxford: Oxford University Press, 2006), pp. 265-281.

${ }^{7}$ In this respect one may want to refer to the groundbreaking works of Michael Bratman. See in particular Michael Bratman, Intentions, Plans and Practical Reason (Cambridge (Mass.): Harvard University Press, 1988), Michael Bratman, Faces of Intention (Cambridge: Cambridge University Press, 1999), and Michael Bratman, Structures of Agency (Oxford: Oxford University Press, 2007). The work of Bratman, which has been widely discussed in legal philosophy in the recent years, has decisively influenced the legal theories of Jules Coleman (see, for instance, The Practice of Principle (Oxford: Oxford University Press, 2001) and Scott Shapiro (see Legality (Cambridge, Mass.: Cambridge University Press, 2011)).

${ }^{8}$ Among those principles they figure prominently the principle of prudence, or self-interest, the principle commanding consistency among one's plans, the principle requiring consistency among one's plans and one's beliefs, and the principle prescribing coherence among one's plans and acts executing one's plans.

${ }^{9}$ Scott Shapiro, Legality (Cambridge, Mass.: Cambridge University Press, 2011), p. 200. 
The conception of law as practical reason has been modelled not only by modest theories of practical reason but also by ambitious ones. A theory of practical reason can be qualified as ambitious, insofar as it is based on the claim that the capacity for rational deliberation is not confined to the management of means given to, as opposed to generated by, reason, but it is primarily concerned with setting and specifying practical ends. On this family of conceptions, practical reason is acknowledged to have the resources to provide the standards for the assessment of the ultimate goals of action. Those standards are, accordingly, rational, qua originating in (the practical use of) reason, vis-à-vis being derived entirely from psychological states that may well be peculiar to some individual agents and alien to others. Ambitious conceptions of practical reason, thus, broaden the scope of rational deliberation in practical affairs.

The broadening has proceeded in two main directions. First, in some variants of the ambitious conception, practical reason refers to the capacity to single out, or determine, which goals one ought to pursue in order for her to be regarded as a rational agent. Paradigmatic, in this sense, is the Kantian conception, which essentially shapes the theory of law as practical reason defended by Alexy, among others. ${ }^{10}$ Secondly, some ambitious conceptions claim that practical reason has the task of specifying the ends an agent may, or ought to, have in a given context. That is, practical reason is taken to be functional to establishing what a wide-ranging goal, which is generally acknowledged to be worthwhile (say, life, happiness, knowledge, friendship, and health), may specifically mean for a particular agent. Practical reason, in other words, is instrumental to settling the specific meaning an abstract human objective has in the particular context where action takes place. This conception of practical reason owes much to the Aristotelian tradition of philosophy. ${ }^{11}$ On the Aristotelian view, the main function of practical reason is not that of determining general practical standards a rational agent ought to conform to, standards from which, it is argued, only generic and next-to-empty maxims of action can ultimately be derived. By contrast, practical reason assists one in the search for one's own ideal of a good life. This ideal, in turn, can hardly be constituted by, and derived from, a set of abstract principles in the fashion of the Kantian conception, since it is intrinsically context-dependent-something bound up with the specific traditions of the community an agent is part of. Accordingly, the fundamental principles of practical reason originate in that which defines the particular identity of an individual or social group. The

\footnotetext{
${ }^{10}$ This view is reconstructed in some detail in Section 3 below.

${ }^{11}$ The Aristotelian view has been powerfully argued for in Alistair MacIntyre, After Virtue (London: Duckworth, 1985), for instance.
} 
Aristotelian approach has shaped conceptions of law as practical reason that have proved to be highly influential in contemporary legal philosophy. ${ }^{12}$ Insofar as the basic principles of practical reason exist only if they are anchored to, and sustained by, norms that enjoy, or have enjoyed for some time, social recognition, law, when it is understood as an instantiation of practical reason, is to a large extent a contingent social practice the legitimacy of which is owed to its capacity to specify and contextualise general rational requirements by so contributing to make them operative and genuinely constraining in a given social setting. ${ }^{13}$

\section{Practical Reason in Alexy's Legal Philosophy}

\subsection{The Notion of Practical Reason and the Law}

The philosophy of law theorized by Alexy is one of those accounts that can hardly be said to proceed independently of a treatment of practical reason. An introduction to the latter is therefore an obvious place to start from in any attempt to understand Alexy's conception of law. Alexy defines practical reason as our capacity to argue, deliberate, and think critically about all the questions that arise as we go about framing a course of conduct, in a context where we must be prepared to defend, and if need be revise, our thinking in response to what others have to say in that regard. ${ }^{14}$ In this definition of practical reason as a deliberative capacity concerned with practical affairs Alexy introduces a distinctive discursive element. For, he further qualifies his definition of practical reason in light of his espousal of discourse theory. This is a procedural theory of practical correctness under which a practical proposition is deemed correct if it can be justified through an argumentative process. The relevant process lies in the discursive practice of asserting a claim and defending it by replying to possible objections in keeping with certain rules and forms - those of rational discourse - that justify the process by making it correspondingly rational. In this way, Alexy establishes a connection between the practical correctness warranted by rational argumentation and the universal agreement that ought to follow: all participants ought to regard as correct the outcome of a discussion that proceeds in keeping with the standards of rational discourse.

\footnotetext{
${ }^{12}$ Within legal philosophy the Aristotelian apporach is explored in John Finnis, Natural Law and Natural Rights (Oxford: Oxford University Press, 1980), John Finnis, Fundamentals of Ethics (Oxford: Oxford University Press, 1983) and John Finnis, "Foundations of Practical Reason Revisited", American Journal of Jurisprudence 50 (205), pp. 109-31 as well as Joseph Raz, Engaging Reason (Oxford: Oxford University Press, 1999) and Joseph Raz, The Practice of Value (Oxford: Clarendon, 2003).

13 This conclusion should not be read as an endorsement of social relativism, since within the Aristotelian approach, practical reason and law account for, but are not constituted by, what is socially and historically contingent. This point is argued at length in Joseph Raz, The Practice of Value (Oxford: Clarendon, 2003), pp. 15-36.

${ }^{14}$ See Robert Alexy, “A Discourse Theoretical Conception of Practical Reason”, Ratio Juris 5 (1992): p. 231.
} 
The standards in question define both the structure and nature of rational argumentation. An argument will be regarded as structurally rational if it is free from contradictions, makes consistent use of terms and predicates, exhibits linguistic and conceptual clarity, relies on true empirical premises, and observes the rules of deductive logic, among other requirements. ${ }^{15}$ These structural standards are described as monological, in that the kinds of argument and the forms of practical reasoning they define are considered sound and rational from the standpoint of a single person thinking and deliberating in isolation from others. By contrast, the standards relating to the nature of practical argumentation - those resulting from an attempt to make explicit what is presupposed in rational discourse-are dialogical rather than monological, for they take into account the other participants in the process of argumentation. In order for an argumentative discourse to be rationally justified under this heading, we must acknowledge each participant's argumentative autonomy, freedom, and equality and must further commit to standards of impartiality and universality. ${ }^{16}$ In summary, two sets of standards (the monological ones and the dialogical ones) state between them, in combination, the fundamental conditions of discursive rationality. Now, discursive rationality not only regulates the way an argument must proceed in order to be rational but also shapes Alexy's notion of practical reason: practical reason is, in this approach, the ability to arrive at correct practical judgments in accordance with the standards of discursive rationality.

Alexy's conception of practical reason can thus be situated within a specific philosophical tradition, the Kantian tradition, wherein practical reason is defined in terms of a human agent's autonomy and is understood to be universal. ${ }^{17}$ But Alexy reinterprets these two features by combining the Kantian tradition with discourse theory: he thus introduces two important changes in framing his own conception of practical reason. In the first place, he gives practical reason what might be called a "communicative twist", by making it an intrinsically dialogical capacity that we can fully exercise only as participants embedded in an intersubjective communicative environment. ${ }^{18}$ In the second place, Alexy does not understand practical rationality in any absolute terms. This feature emerges in particular from his critique

\footnotetext{
${ }^{15}$ These and other structural requirements go into what Alexy calls a code of practical reason, for a summary statement of which see Robert Alexy, A Theory of Legal Argumentation (Oxford: Clarendon, 1989; or. ed. 1978), pp. 199-204.

${ }^{16}$ On the dialogical standards of practical reason see Robert Alexy, "A Discourse Theoretical Conception of Practical Reason", Ratio Juris 5 (1992): p. 235, for instance.

${ }_{17}$ Alexy's own statement of the Kantian roots of his conception of practical reason can be found in Robert Alexy, "Discourse Theory and Human Rights", Ratio Juris 9 (1996): pp. 209-11.

${ }^{18}$ The inescapably dialogical or participatory nature of reasoning (as against the monological mode of reasoning) is set out in Robert Alexy, "Problems of Discourse Theory", Critica 58 (1988): pp. 51-53. There are two important reasons that Alexy adduces in support of this view (see Robert Alexy, "A Discourse Theoretical Conception of Practical Reason", Ratio Juris 5 (1992): pp. 237-38).
} 
of the thesis that for each practical question there can only be one correct answer. ${ }^{19}$ In this context, consistently with his dialogical model Alexy argues that rational discourse does not function like a formula, where you plug in the numbers and out comes a single solution for each practical problem to be solved, nor can rational discourse ensure that the solutions it yields are final and conclusive. This is because the rationality of practical discourse is judged not so much by its final outcome as by the process through which that outcome is reached. As mentioned, this is a discursive process framed by a set of standards and structural constraints, and while these standards and constraints do ensure a rational outcome, they allow a good measure of flexibility owed to the fact that $(a)$ the standards function as models for us to follow, or approximate, as best we can, rather than as rigid criteria that we either satisfy or do not satisfy, which means that their fulfilment can only be partial; $(b)$ the standards do not dictate all the steps in a practical argument; and $(c)$ what the standards end up prescribing depends importantly on context, that is, on the interests, beliefs, and assumptions from which the participants in any discourse proceed in their deliberation, and these premises clearly vary according to the participants involved. ${ }^{20}$ Alexy's discourse-theoretical model of practical reason therefore does not yield a single, foolproof solution for each practical problem, nor is it designed to do so. It only assumes, by contrast, that there is a correct way to go about solving such problems. It is thus essential to practical discourse that even though it does not impose a single outcome, it does prescribe a method, grounded in the principles previously mentioned, thereby acting as a regulative idea, namely, as something that guides and orients our argumentation in practical affairs. Alexy's dialogical conception of practical reason, hence, defines an open-ended procedural ideal that, while rational, does not thereby set up a framework of absolute certainty but allows for some indeterminacy, with outcomes accordingly amenable to revision. This indeterminacy, which is owed to the structural limitations inherent in the discursive model of practical reason, poses a problem, since the indeterminacy and uncertainty we wind up having in the outcome means that we must still find an effective way of settling disputes. The guidance secured by practical reason therefore needs to be integrated with further standards and procedures that, while not entirely rational, do ensure a definite outcome. And this is why law is needed.

\footnotetext{
${ }^{19}$ See Robert Alexy, A Theory of Legal Argumentation (Oxford: Clarendon, 1989; or. ed. 1978), pp. 206-8.

${ }^{20}$ On the structural indeterminacy of rational discourse, see Robert Alexy, "Problems of Discourse Theory", Critica 58 (1988): pp. 47-48, where it is pointed out that "first, the rules of discourse contain no prescriptions concerning the starting points of the procedure. Starting points are the normative convictions and interpretations of interest of the participants, just as they appear. Second, the rules of discourse do not prescribe all steps or argumentation. Third, a number of the rules are only approximatively fulfilable. Thus discourse theory does not guarantee a definite decision in each case".
} 
A legal system therefore is to be considered a matter of practical rational necessity, since the procedures designed to translate into action the principles of practical reason are indeterminate, and yet we still need to find conclusive practical solutions that we can converge on and put into practice. This should not be taken to mean, however, that once practical reason has done its service in setting up a legal system, it thereby retreats. On the contrary, it pervasively affects the structure and contents of the very device - the law-which we turn to in making up for its indeterminacy. Law and practical reason are in this sense bound by a mutual dependency, since on the one hand practically rational "discourse needs the law to gain reality" and on the other hand "the law needs [practically rational] discourse to gain legitimacy". ${ }^{21}$

The connection between practical reason and law therefore stems from the discursive necessity of institutionalizing the principles of practical reason. The upshot of this understanding of law as an institution shaped and constrained by practical reason is that, while there is a broad range of contents law can take, it cannot take just any content or develop in any form whatsoever, since "in a rational discourse not all legal systems can be justified, but only those that fulfil the elementary demands of practical rationality". ${ }^{22}$ Thus, as an institutionalization of practical reason - that is, as a formal means by which to instantiate, specify, and supplement the principles of practical reason-law comes out having only a limited and partial autonomy. ${ }^{23}$ In a nutshell, then, Alexy brings practical reason to bear as a pervasive component of law. Which is to say that practical reason plays a pivotal role in his legal philosophy, enabling him not only to make the case that there is a rational way in which we can go about dealing with practical matters, but also to take a comprehensive view of law as an enterprise firmly embedded in the wider practical setting in which we all operate.

\subsection{The Foundation of Practical Reason}

In consideration of the fact that the notion of practical reason plays a central role in Alexy's legal philosophy (and in a number of other contributions to the conception of law as practical reason too) one must at this point take a step back and reflect on the possibility of practical reason itself. For, the very possibility of practical reason is something the contemporary philosophical debate has called into question, with some commentators finding

\footnotetext{
${ }^{21}$ Robert Alexy, "My Philosophy of Law: The Institutionalisation of Reason", in L. J. Wintgens (ed.), The Law in Philosophical Perspective (Dordrecht: Kluwer, 1999), p. 35.

${ }_{22}$ Robert Alexy, "Legal Argumentation as Rational Discourse" Rivista Italiana di Filosofia del Diritto LXX (1993): p. 174.

${ }^{23}$ On this point, see Robert Alexy, "A Discourse Theoretical Conception of Practical Reason", Ratio Juris 5 (1992): pp. 244-48, Robert Alexy, "Legal Argumentation as Rational Discourse" Rivista Italiana di Filosofia del Diritto LXX (1993): pp. 174-75; and Robert Alexy, "My Philosophy of Law: The Institutionalisation of Reason", in L. J. Wintgens (ed.), The Law in Philosophical Perspective (Dordrecht: Kluwer, 1999), pp. 35-38).
} 
practical reason to be an illusory and even contradictory notion, one that does not stand rigorous critical scrutiny and at best performs an ideological and deceitful function. A reply to this line of scepticism requires one not only to frame a conception of practical reason (such as the one we have just considered) but also to provide a foundation for it, showing that practical reason is possible and necessarily so. So, Alexy engages directly with this issue, which for him means grounding the principles of discursive rationality, since it is on the basis of those principles that, in his construction, practical reason is itself forged and grounded. In this foundational effort, Alexy proceeds coherently with his Kantian premises by relying on a transcendental form of argument, that is, an argument whose starting point is a presupposition widely acknowledged to be necessary, a presupposition from which a necessary consequence is derived, such that the consequence shares the same necessity with the presupposition. ${ }^{24}$

Alexy frames his argument by noting, to begin with, that we cannot argue without making assertions: practical discourse, in other words, necessarily presupposes the speech act of making assertions. This speech act — a pragmatic unit—is thus used as the starting point of Alexy's argument (accordingly described as a transcendental-pragmatic argument). From here Alexy crucially singles out another necessary presupposition, observing that we cannot assert anything while believing this assertion not to be true or correct. The impossibility involved is not a logical one but a pragmatic one. Stated otherwise, if it were at all possible to assert $a$ while believing non- $a$, we would run into the performative contradiction, whereby the content of our assertion, $a$, is defeated by our belief that the assertion is false or wrong (by our belief that non- $a$ ). Which latter belief contradicts the prior, enabling condition of our making the assertion in the first place, a condition requiring us to believe that the assertion is true or correct. ${ }^{25}$ By so analyzing the presuppositions involved in making an assertion, one can extract the pragmatic consequence that in making an assertion (understood as a speech act) individuals thereby commit themselves to the truth or correctness of what they are asserting. This means that the making of assertions incorporates a necessary claim to truth or correctness.

\footnotetext{
${ }^{24}$ Alexy's transcendental argument for the foundation of practical reason thus uses the method of presupposition analysis, an idea first set out in A. Watt, "Transcendental Arguments and Moral Principles", Philosophical Quarterly 25 (1975), pp. 40-57. Alexy's argument can be found in Robert Alexy, "A Discourse Theoretical Conception of Practical Reason", Ratio Juris 5 (1992): pp. 238-44, and Robert Alexy, "Discourse Theory and Human Rights", Ratio Juris 9 (1996): pp. 212-20. For a general introduction to the transcendental form of argument, see Barry Stroud, "The Goal of Transcendental Arguments", in R. Stern (ed.), Transcendental Arguments: Problems and Prospects (Oxford: Clarendon Press, 1999) and R. Stern, Transcendental Arguments and Scepticism (Oxford: Clarendon, 2000), among others.

${ }^{25}$ To be sure, we could conceivably contradict this presupposition; that is, we could assert $a$ while believing non$a$, but $a$ would at that point no longer count as an assertion: it would instead be a lie, a different speech act altogether, one that would move us away from the practice of rational argumentation and into that of deceit.
} 
One can frame this conclusion within the context of discourse by noting that any claim to truth or correctness made in such a context is a claim that can be challenged by argument. The making of an assertion, hence, ultimately commits one to be ready and willing to justify what she asserts, by offering reasons in support of the claim that her assertion is true or correct: with the speech act of making an assertion comes an obligation to justify the assertion. As long as the claim to truth or correctness causes the speech act of making assertions to incorporate a claim to justification, this speech act can be constructed as one involving the practice of giving reasons. This in turn makes the same speech act (that of asserting) the gate through which we enter the argumentative domain: the moment we assert anything, we are thereby committed to justifying it - by proffering reasons for it - and to do so is to move into the territory of argumentation.

One can take this even further by also noting, importantly, that the realm of argumentation is governed by a set of underlying principles, prominent among which are $(a)$ equality, meaning that all the interlocutors in a genuine argumentative practice are accepted as equals; (b) universality and impartiality, meaning that a reason can secure an authentic justification only if everyone comes to see it as a good reason; (c) autonomy, meaning that the equal participants are regarded that way on account of their ability to reason on their own, identifying on their own the best principles on which to base their reasoning; and $(d)$ freedom from force, meaning that justification relies on moral and logical force alone, and would no longer count as such under conditions of physical force or duress. Hence, if one's making an assertion necessarily entails a claim to truth or correctness, it also necessarily entails a claim to equality, universality, impartiality, autonomy, and freedom - these claims being no less necessary in making the speech act of asserting than this speech act is in engaging in discourse. Since discourse forms the essential fabric of our everyday life in society-it is the most basic form of social life among humans, in that there is barely any situation in which we can do anything without communicating and stating what is the case or what we believe to be the case-it follows that the making of assertions is necessary to our participation in the human form of life.

It is a key role that this observation plays in Alexy's argument: if $(i)$ in the discursive practice of argumentation lies the most basic form of social existence among humans (meaning that we could hardly exist as humans without this practice), and if (ii) this practice necessarily entails our making assertions and giving reasons when called on to do so, and if (iii) this in turn means that we must necessarily engage with others on an equal footingtaking into account the principles of equality, universality, impartiality, autonomy, and 
freedom - then (iv) these principles (despite what the sceptics claim) are not only possible but also necessary (within the basic form of human life). And since these principles are constitutive of practical reason, practical reason proves to be both possible and necessary (within the most basic form of human life).

\section{An Internal Criticism of Alexy's Foundation of Practical Reason}

There is much insight to be gained from Alexy's effort to shed light on the nature of law by not only establishing an inherent connection between law and practical reason but also defining law as an institutionalization of practical reason. However, this construction also means that a conception of law requires a strong foundation for practical reason, qua the basis of law. And this is precisely where Alexy's project shows some weaknesses, because the transcendental argument on which he grounds practical reason is explicitly toned down in a couple of respects by comparison with standard transcendental arguments.

Transcendental arguments come in different forms. The form Alexy uses for his foundation of the principles of practical reason consists in (1) taking a starting point that everyone in some way regards as being all but necessary (our making assertions); (2) singling out a necessary presupposition of that starting point (our compliance with the basic principles of practical reason); and (3) concluding that this presupposition, figuring in the premises of the starting point, is likewise necessary. So the argument is that if we necessarily must engage in the speech act of making assertions, and if this speech act presupposes the principles of practical reason, then we must acknowledge that these principles necessarily operate in the background (enabling us to make assertions in the first place) and that they are accordingly necessary. ${ }^{26}$ The strength of this form of transcendental argument hinges on the premises, which here consist in the assumption that most of us, most of the time will want to make assertions or will otherwise find it necessary to do so as participants in a discursive practice that makes up the most basic form of human life. To the extent that this starting point is necessary, so will the conclusion be made to derive from that premise. And that is precisely where Alexy's transcendental argument reveals itself to be weak, in its premises. Indeed, as Alexy himself concedes, it is with a grain of salt that we are to take the claim that the starting point of his argument - the speech act of making assertions, understood as the point of entry

\footnotetext{
${ }^{26}$ The structure of the argument, then, is that of modus ponens. For an overview of the forms of transcendental argument, see C. Illies, The Grounds of Ethical Judgment: New Transcendental Arguments in Moral Philosophy (Oxford: Oxford University Press, 2003) and Corrado Roversi, "Constitutionalism and Transcendental Arguments", Northern Ireland Legal Quarterly 59 (2008), pp. 109-24.
} 
into the realm of argumentation - is to be considered something we must commit to as a matter of pragmatic necessity.

More to the point, Alexy's foundation of practical reason is explicitly conditioned on each person's recognition of her interest in participating in the practice of argumentation (the interest in correctness, as Alexy calls it). For, whilst the practice in question is regarded by Alexy as the most basic form of life among humans - it is something that we cannot abstain from in our ordinary existence-discursive engagement with others is not what we necessarily must practice all the time in order to live as humans. It is rather something we ordinarily practice, namely, something we practice most of the time. It is Alexy's view, then, that each of us could conceivably at any point resolve to withdraw from argumentation (once, occasionally, or even on a regular basis) and live a life where we assert close to nothing. Of course, this would be an entirely different form of life from the one most of us are accustomed to, where discursive interaction matters, but it would still be a life. What is more, our withdrawing from such interaction (and from the asserting that necessarily accompanies it) does not have to be blunt: we could withdraw to some extent while still retaining the basic form of human life. So, it is only for those of us who express an interest in correctness-for those of us who are committed to consistently participating in the basic form of human life as framed by the discursive practice of argumentation - that our satisfying what practical reason demands of us in Alexy's weak transcendental-pragmatic argument becomes a matter of necessity.

Crucially, we cannot rely on a transcendental strategy in showing that this commitmentone's interest in correctness - is necessary. As Alexy explains it,

no transcendental argument can generate interests or motivations. Under the aspect of reality or facticity the transcendental argument therefore leads only to a hypothetical validity of the discourse rules: it shows what is valid if there is an interest in moral correctness and if therefore the ideal point of view of correctness is taken up. That is a factually limited validity. ${ }^{27}$

To be sure, our moral interest in correctness can at least be shown not to be arbitrary; that is, we can show that it makes rational sense for us, as a matter of prudential calculus, to commit ourselves to the rules of discourse. But this means we have to buttress the primary transcendental argument by introducing utility-based prudential considerations. In other

\footnotetext{
${ }^{27}$ Robert Alexy, “Discourse Theory and Human Rights", Ratio Juris 9 (1996): pp. 218-9.
} 
words, we have to bring in the strategic argument that, while we cannot expect everyone to have an interest in correctness and regard the principles of practical reason as necessarily valid, those who do engage in this practice - taking part in the most basic form of human life by making assertions and argumentatively supporting them with reasons when needed - stand to benefit by maximizing their individual utility. To see this, we need only consider that even those people who are not genuinely and sincerely interested in moral correctness do still have an interest in maintaining an appearance of correctness: this applies to dictators and even to shrewd politicians, for example, who ostensibly espouse the principles of practical reason, making an effective use of arguments and assertions, but only to push through an agenda which they want to conceal and in which lies the utility they seek to maximize. Thus, if we do not commit to practical reason out of a genuine interest in moral correctness, we will do so (at least on the face of it) out of an interest in maximizing our own utility. Since the latter can on empirical grounds be claimed to be a deep-seated interest, likewise deep-seated will be our drive to make assertions and back them up with arguments.

In sum, Alexy's foundation of practical reason couples a primary transcendentalpragmatic argument with empirically based utilitarian and prudential considerations: the argument consists in showing that practical reason is a capacity that in one way or another we all have to make use of, either because we have a genuine interest in correctness or a strategic one. Either way, whether out of a genuine commitment or out of prudential choice, we will want to ordinarily take part in that most basic form of human social life that compels us to make assertions and support them with reasons, thereby also complying with the basic principles of practical reason.

A foundation supported by the argument just introduced is, one can readily appreciate, doubly weakened. ${ }^{28}$ In the first place, Alexy softens his claims concerning the necessity of practical reason by saying that only in those cases where someone does not live in total isolation and, in addition, has an interest in argumentative correctness or in individual utility is there a pragmatic necessity to make assertions and hence to enter the domain of argumentation. But otherwise, if one does not have that interest, there is nothing selfdefeating or self-contradictory about her not making assertions and hence not interacting with others on an argumentative basis. In the second place, Alexy concedes that even when we find ourselves in the ordinary circumstance of having an interest in correctness or in maximizing

\footnotetext{
${ }^{28}$ The two noteworthy limitations to the validity of practical reason are introduced in Robert Alexy, "A Discourse Theoretical Conception of Practical Reason", Ratio Juris 5 (1992): pp. 241-43, and Robert Alexy, "Discourse Theory and Human Rights", Ratio Juris 9 (1996): pp. 217-20, for instance.
} 
our own utility, this does not mean that we must without exception make assertions anytime we happen to be interacting with someone in an argumentative context. This is to say that we can be selective in choosing whom to be argumentative with: not in all those contexts in which argumentation matters as a basic form of activity do we have to be argumentative, despite the fact that we otherwise have an interest in being that way.

Alexy's first concession weakens his foundational argument, but only to some extent. All it says is that there are occasional circumstances where someone may in fact live in isolation and fail to have a genuine interest in the correctness of assertion-making or a strategic interest in making assertions for any purposes of individual utility. The scope of this concession is, for all practical purposes, rather narrow, especially in the actual world we inhabit, where it is only a handful of people who live in a state of reclusion and might not have an interest in discursive correctness or in maximizing utility by showing themselves to be discursively correct. So, whereas Alexy's first concession does mean that his transcendental argument cannot properly ground the necessary validity of practical reason, it at least provide a quasinecessary foundation, since in the world we are familiar with (and, most importantly, in the world a legal-philosophical project is concerned with) people do ordinarily have the moral or utilitarian interest on which basis we can claim that the principles of practical reason are valid and necessary.

It is Alexy's second concession that really puts his foundation of practical reason on shaky ground. Alexy concedes that even in ordinary circumstances - that is, even when we have an interest in making assertions, and making them consistently with the underlying principles of practical reason-we may still legitimately disregard those principles on occasion, and that without even giving a special justification for doing so, other than that we may not find it convenient on a given occasion, or that we might not particularly care about those with whom we happen to be engaged in discourse, or whatever. This is to claim that the underlying principles of practical reason cannot be counted as presuppositions at all but rather they function more like desiderata. For, if we can disregard these principles, even only occasionally, all the while continuing to be part of that most basic form of human social life which lies in our ability and willingness to engage in argumentation, then $(a)$ these principles are not really necessary and $(b)$ the basic form of human life must either be not so basic (as Alexy's first concession seems to imply) or it must be more an ideal than a form of existence (as this second concession seems to suggest).

True, Alexy does claim that we need an overall discursive disposition to treat others as partners in argument if we are to be recognized as participants in that basic form of life; that 
is, we have to generally espouse and follow the basic principles and standards of practical reason if we want to consider ourselves partners in discourse. But this is not enough to establish the necessity of the principles constitutive of practical reason. To this end, we would have to show that our interest in making assertions in keeping with the principles of practical reason is not so much an interest, but an enabling condition, that is, a presupposition, such that at no time, ever, can such principles be disregarded if we are to make assertions and participate in a discursive practice of the kind Alexy envisions.

So, by envisioning the possibility of departing from the demands of practical reason without ipso facto renouncing one's participation in the most basic form of human life - and, then, by requiring that only sometimes do we have to make assertions and take part in the justificatory game in order to consider ourselves participants in the most basic form of human life-Alexy in effect concedes that the principles of practical reason are not, after all, necessary. ${ }^{29}$ For, necessity means that we cannot choose to do otherwise. Therefore, as long as making assertions is to be regarded as necessary we cannot choose not to engage in the practice of making assertions and backing them up with arguments when taking part in an argumentative-discursive practice. Conversely, if no serious consequence attaches to our failure to act in a discursive fashion, then we know that the underlying principles (the principles of practical reason) are not necessary. Since there is no such consequence in Alexy's construction - in that we can occasionally deviate from practical reason and still account ourselves to be genuine agents in the practical domain-it follows that Alexy's transcendental-pragmatic argument cannot ground the necessary validity of the principles of practical reason.

\section{Theorising an Alternative Foundation Practical Reason}

One way to respond to the criticism that Alexy's transcendental argument ultimately fails to set the principles of practical reason on a secure foundation by thus succeeding to show these principles to be necessary may simply consist in the acknowledgment that no such foundational project is ever going to find the bedrock of necessary validity it hopes to find. This is certainly one lesson we may take away from Alexy's strategy: his discussion may be interpreted as illustrating that our acting in accordance with practical reason ultimately turns out to be a matter of choice rather than something we necessarily ought to do. This does not

\footnotetext{
${ }^{29}$ This possibility is explicitly conceded in Robert Alexy, “A Discourse Theoretical Conception of Practical Reason", Ratio Juris 5 (1992): p. 241, where it is stated that only someone who "fails ever to make an assertion ... and ever to put forward an argument" forfeits her participation in human life (emphasis in original).
} 
mean that any foundation of practical reason is thereby arbitrary. Our decision to act in accordance with practical reason is ultimately a decision, to be sure, but it is not just any decision, for it is grounded in something which may not pass the test of necessity but which can nonetheless be acknowledged to have a solid basis, since it finds practical support in practices and interests having wide currency among human beings.

This is precisely the direction Alexy seems to have taken in recent years, laying emphasis on the role that decisions play in structuring the space of practical reason. ${ }^{30}$ The idea, on this view, is that practical reason defines a space-Alexy calls it the space of the discursively possible - which sets boundaries delimiting what can count as discourse and what cannot, in pretty much the same way as the principles of practical reason characterize practical reason itself, except that now the focus is not on the preconditions of practical reason-its necessary premises - but on the decision to conceive ourselves as "discursive creatures" and to conduct ourselves accordingly. Alexy describes this as an "existential decision". ${ }^{31}$ In this decision lies the appeal and normative force of practical reason, for the decision to act in keeping with the principles of practical reason, or discursive rationality, is ultimately a decision about the kinds of agents we want to be and so something we, qua practical creatures, find compelling and will accordingly want to embody. So, as much as the decision to be discursive agents cannot be constructed as necessitated by purely rational considerations (for it is just that, a decision, i.e. an act of the will), it does take us into a realm which is rationally constrained, the realm of practical reason as defined by the principles of discursive rationality.

As tempting as this route may be, it is not the only available option in seeking to ground practical reason, nor does it very much agree with a conception of law as practical reason informed by the fundamental claims underpinning the Kantian practical philosophy (a philosophy that Alexy substantially endorses). An alternative, genuinely Kantian, option consists in reframing Alexy's transcendental-pragmatic argument in such a way as to make any departure from the principles of practical reason illegitimate and unjustified. An argument so structured will have to show that the moment we disregard the principles of practical reason, we will thereby have compromised our pragmatic standing as human agents, with the result that even an occasional or temporary violation of such principles cannot be justified. If one can show that - namely, if one can show that even a single act in violation of practical reason will estrange an acting individual from the human form of life, to the effect that she

\footnotetext{
${ }^{30}$ See Robert Alexy, "Reflections on How My Thinking about Law Has Changed over the Years", available at http://www.tampereclub.org/wordpress/?p=9 (last accessed on 20 August 2013), pp. 14-7.

${ }^{31}$ Robert Alexy, "Effects or Defects: Action or Argument? Thoughts about Deryck Beyleveld and Roger Brownsword's Law as a Moral Judgement”, Ratio Juris 13 (2006), p. 174.
} 
can no longer claim a status as a distinctively human agent—one will be able to conclude that the demands of practical reason are necessarily valid. It is to this alternative strategy, more in keeping with Kant's own foundational efforts, that the rest of this section will be devoted.

Exploring an alternative to Alexy's weak foundation of practical reason from a standpoint internal to the Kantian tradition of practical philosophy commits us to look for a more robust transcendental argument. In so doing, however, one cannot follow the path originally delineated by other advocates of discourse theory, such as Karl-Otto Apel and Jürgen Habermas. ${ }^{32}$ For, as Alexy has convincingly argued, those programmatically stronger transcendental foundations are based on contestable premises that render them unviable. ${ }^{33}$ So I instead suggest integrating and fortifying Alexy's project through an alternative foundation of practical reason, a foundation that is based on a constitutivist theory of practical reason. ${ }^{34}$ By constitutivism I mean the view that an intrinsic connection exists between the principles of practical reason and the defining features of human agency, to which those principles ultimately owe their validity, or bindingness. This intrinsic connection is such that our acting in accordance with the principles of practical reason is in part what it is to be a human agent, an idea expressed by saying that these principles constitute our agency. It follows that any violation of these principles - any failure to comply with what practical reason demandswill carry with it the consequence that we cease to be who we essentially are in the practical sphere. Any such failure, in other words, will disqualify us from our status as agents. Not unlike discourse theory, constitutivism moves from premises internal to the Kantian philosophy and makes extensive use of transcendental arguments to ground the validity of the principles of practical reason. Their theoretical premises are thus fully coherent with those underpinning the Kantian version of the conception of law as a practical reason such as Alexy's. This theoretical affinity backs up and legitimizes my suggestion to rely on a constitutivist argument to ground the conception of law as practical reason.

\footnotetext{
${ }^{32}$ See Karl-Otto Apel, "Das Apriori der Kommunikationsgemeinschaft und die Grundlagen der Ethik" in Idem, Transformation der Philosophie, vol. 2, (Frankfurt: Surkhamp, 1973), pp. 358-435 and Jürgen Habermas, "Diskurethik: Notizien zu einem Begründungsprogramm", in Idem, Moralbewusstsein und kommunikatives Handeln (Frankfurt: Surkhamp, 1983), pp. 53-125.

${ }^{33}$ See Robert Alexy, "A Discourse Theoretical Conception of Practical Reason”, Ratio Juris 5 (1992): pp. $237-$ 38, and Robert Alexy, "Discourse Theory and Human Rights", Ratio Juris 9 (1996): pp. 217-19).

${ }^{34}$ The constitutivist view is defended in David Velleman, Practical Reflection (Princeton: Princeton University Press, 1989), David Velleman, The Possibility of Practical Reason (Oxford: Oxford University Press, 2000), Christine Korsgaard, Creating the Kingdom of Ends (Cambridge: Cambridge University Press, 1996), Tamar Schapiro, "What Is a Child", Ethics 109 (1999): pp. 715-38, Tamar Schapiro, "Three Conceptions of Action in Moral Theory", Nous 35 (2001): pp. 93-117, Connie Rosati, "Agency and the Open Question Argument" Ethics 113 (203), pp. 490-527, Luca Ferrero, "Constitutivism and the Inescapability of Agency", Oxford Studies in Metaethics 2 (2009), pp. 303-33, Christine Korsgaard, Self-Constitution (Oxford: Oxford University Press, 2009), and David Velleman, How We Get Along (Cambridge: Cambridge University Press, 2009).
} 
The constitutivist argument that, in my view, can both grant the necessary validity of the principles of practical reason and is coherent with Alexy's framework of (legal) thought puts the very concept of a human agent front and centre. Human agency, especially when it is understood as a pragmatic notion vis-à-vis a metaphysical idea, in turn requires a definition of action, since from the pragamatic perspective human agency stands for the range of essential capacities making for the possibility of action (in a full-fledged sense) - a human agent is in essence a person capable of action as framed by the relevant conditions enabling an individual to perform a specific kind of conduct. This argumentative strategy makes human agency derivative from action. This is to say that the point of departure of the constitutivist argument I intend to introduce here is action, which accordingly need be analytically clarified in detail before proceeding any further.

As a generic term, "action" is ordinarily taken to mean anything done: any deed, act, or conduct engaged in. In this generic sense, "action" stands for a loose term referring to something that is done. The meaning of "action" I am using in the constitutivist argument that follows is instead more specific and therefore technical. It refers to a central type of doing: a privileged class designating what may be considered the "paradigmatic sense of undertaking", or "conduct par excellence". This "central type of action" can be arrived at and spelled out through a comparative strategy, namely, by considering different kinds of human conduct and comparing their main features. ${ }^{35}$ I will then work from the simplest case of action, the most elemental, to the paradigm case.

The most basic form of doing from which one can start is what might be called spontaneous conduct, namely, uncontrolled conduct that is neither intentional nor driven by any purpose, examples being blushing, hiccupping, and blinking. While spontaneous movements do count as action in a generic sense-they always involve someone doing something - they tend to simply "happen" or "come about" in an event-like manner, in that the subject with whom they originate is playing a passive role. For something that will more closely resemble conduct performed by an "active" self, we have to at least introduce purpose and control into one's doing. Purpose and control narrow our range down to a kind of conduct that might be called reflexive, namely, conduct dictated by our reflexes. However, as much as reflexive conduct may require an active role on our part, it is not an expression of what we intend to do. This characterization sets the stage for the next level, where we find a doing that

\footnotetext{
35 This manner of proceeding is standard in action theory: see, for example, David Velleman, "Replies to Discussion on The Possibility of Practical Reason", 121 Philosophical Studies 3 (2004), pp. 281-3. See also Joseph Raz, Engaging Reason (Oxford: Oxford University Press, 1999), pp. 22-3.
} 
is controlled and purposive as well as intended. In contrast to reflexive conduct, this form of doing comes about as a result of a thinking - a pondered moment of decision - and can therefore be described as knowingly carried out. Conduct at this level can be qualified as reactive, not just reflexive, since its mechanics are those of an intentional response to a certain state of affairs, a response driven by forces internal to us - the incentives. ${ }^{36}$

As much as control, purpose, and intention may be central to our practical mode of existence, and may account for a large part of it, they do not account for the whole of it nor, for that matter, do they make up the core of what I consider to be the central type of action for a human being (and so the shaping hand of human agency). In order to get there, we need a further, accreting element whose incorporation yields what I will call principled conduct, for it consists in conduct that depends essentially on our adopting general standards, policies, guidelines, or plans. These might cumulatively be referred to as "principles", thus understood as general practical standards protected from the pressure of incentives. In principled conduct, we do not simply react or adapt to an internal stimulus or external environment; we instead proceed from a general guideline that informs our decisions as to the conduct to be undertaken. Hence, principled conduct differs from reactive conduct by bringing into play a further element that mediates between stimulus and response, and opens up a space in which we can choose to act differently from the way in which occasional incentives might dictate given the situation at hand. Ultimately, it is this further element that introduces the central type, or paradigmatic form, of conduct which I am calling action.

As anticipated, on the pragmatic approach taken here a human agent is anyone capable to embark into the central type of action. This capacity for action we have as human agents is such that we can engage in conduct framed in light of general standards providing guidance. Human agency is thus defined as an ability to perform action (in the paradigmatic sense of this term). Conversely, if we can perform action, we owe it to our possessing certain dispositional capacities that function as prerequisites, or preconditions, for action. In this sense those dispositional capacities are constitutive of human agency, in that no action, and hence no acting person, and so human agent, would be possible without them. Let us see, then, how human agency can be characterized through these necessary enabling capacities.

The first of these basic capacities can be invoked by considering that principles - the distinctive traits of action as just introduced - cannot be worked out by a reliance on perception alone, that is, on an ability to receive sensory data from the environment and

\footnotetext{
${ }^{36}$ Here "incentive" is, then, used as a a broad term which I take to include any number of pattern-like instinctive impulses, feelings, drives, desires, and inclinations.
} 
identify them as being of one sort or another. If we are to frame practical principles, we need to be able to have a representation of the world more articulated than that which mere perception makes possible. This means that it will also be necessary to reflect on external stimuli. Hence the first precondition of action: a capacity for reflection, or reflectivity, understood as the general capacity to think before we act and so to take a critical standpoint from which to assess a situation. ${ }^{37}$

Reflectivity links up conceptually with another capacity that need be introduced to account for the whole of what enables us to engage in action, and so for what is distinctive about human agency. Reflectivity, in enabling us to reflect on our conduct, gives us as well an ability to reflect on our selves. In turn, reflection on our selves, or self-reflection, gives us self-consciousness, a turning inward on oneself and one's inner states. ${ }^{38}$ And in humans selfconsciousness takes a specific form of awareness: the awareness of one's self as composite, namely, as made up of mutually irreducible components. Self-consciousness, in other terms, enables each of us to see that even though the self functions as a whole, it does not form a single, undifferentiated substance but is rather compound-its components being our different incentives. Through this discovery we come to appreciate that the unity of the self consists not in a state given to us but in a construction: a composition and synthesis by which we work together our multiple elements. These elements exert on us forces that drive our conduct in different directions not necessarily compatible or coherent with one another. Hence the synthesis needed to achieve continuity of action: we will not have any coherent conduct unless we can reduce to unity (or at least to a working whole) the forces operating within our selves. ${ }^{39}$ In order to achieve unity we must prioritise, and prioritise consciously, by so establishing among the elements of the self a ranking on which basis to determine what course of conduct we should take on any given occasion. ${ }^{40}$ This effort in turn requires reasoning and deliberation. For in order to prioritise the constituents of the self, we must take

\footnotetext{
${ }^{37}$ Reflectivity provides a mediating element by which we are enabled to step back and have a perspective on the situation before us, in such a way that we are not boxed into the blind mechanism of stimulus and reaction by so taking into account standards we endorse. As Connie Rosati puts it, a reflecting self "comes to dissociate herself from some of her desires, motivations, and traits, while identifying with others. This capacity to step back, to engage in self-reflection, gives persons a kind of freedom from identity with their immediate activities or their immediate motivational tendencies". C. Rosati "Naturalism, Normativity, and the Open Question Argument" Nous 29 (1995), 61.

${ }^{38}$ Self-consciousness is considered a distinctive element of human agents in Christine Korsgaard, SelfConstitution (Oxford: Oxford University Press, 2009), pp. 109-32, where the subject is treated extensively, and my own treatment of it here owes much to Korsgaard's philosophical account of the self and the idea of selfconstitution. But this should not be taken to suggest that Korsgaard would endorse my reading of her texts.

${ }^{39}$ On this requirement, calling for unity of action, see Christine Korsgaard, Self-Constitution (Oxford: Oxford University Press, 2009), pp. 18-26.

${ }^{40}$ On the need to prioritize, see Christine Korsgaard, Self-Constitution (Oxford: Oxford University Press, 2009), pp. $107-8$.
} 
into account not only our raw instinctual powers but also the resulting course of conduct and what it leads to - the advantages and disadvantages it carries - thus taking the larger picture into view. This requires some kind of reasoning, an evaluation of the reasons for and against conducting ourselves in this or that way. ${ }^{41}$ Human agents thus have a capacity for reasoned conduct.

While this capacity - the capacity of reasoned conduct - can ultimately be said to originate in reflectivity, it moves beyond that point. Reflectivity may well enable us to ponder on the pull of the incentives, but with the capacity for reasoned conduct we can go further and remake those incentives into reasons. This further capacity I will call rationality, by which I mean one's ability to heed, grasp, handle, and respond to rational pressures by working with, processing, and acting from them. Rationality enables us to recognise practical principles and take them into account as determinants of conduct by building them into our general framework of action and accordingly giving them the proper practical weight. It is therefore through rationality that some of the forces bearing on action are endowed with a distinctive significance and are prioritized over other influences. As a result, the pressure exerted on us by incentives can be considered akin to a proposal for action, one that we can rationally filter and fashion into some principle by synthesizing and unifying the medley of items making up the proposal. In this way, for one thing, rationality makes it possible to understand principles as the genuine ultimate basis of action; for another, we can be described as the authors of our own conduct in such a way that we-rather than our incentives - ultimately determine what to do. ${ }^{42}$

With these points made, we have the groundwork on which to build the concept of human agency. The argument so far has been that action is not only controlled, purposeful, and intentional but also principled; that principled conduct is made possible by reflectivity; that reflectivity produces self-consciousness; that self-consciousness makes an agent aware of the internal components of the self (the incentives); and that this awareness - enabling agents to lead an existence distinct from that compelled by the contingent forces internal to their selves - brings with it a peculiar capacity: rationality. This means that rationality comes into play alongside reflectivity in constituting human agency and providing its most basic content. From which follows an understanding of human agency as the capacity to act on self-imposed reasons, reasons agents have worked out by exercising their reflectivity and rationality.

\footnotetext{
${ }^{41}$ On this need to reason and deliberate, see Christine Korsgaard, Self-Constitution (Oxford: Oxford University Press, 2009), pp. 120-1.

${ }^{42}$ For further elaborations on this theme, see Christine Korsgaard, Self-Constitution (Oxford: Oxford University Press, 2009), pp. 109-32.
} 
Now, the fact that rationality is a constitutive element of human agency explains why within the practical domain the fundamental principles of practical reasons-namely, the defining principles of rationality in its practical use - are inescapable for any one of us. The principles of practical reason are valid for, or binding on, us, since we are human agents and by their own constitution human agents partake of rationality. To put it otherwise, the demands of practical reason bind any human agent, qua reflective self, capable to rationally shape her own conduct. One is bound by the principles of practical reason, since no one can be regarded as a distinctively human agent unless she is capable of conforming to the requirements issuing from practical reason. The defining principles of rationality-including rationality in its practical use - are, then, constitutive of human agency: human agency can come into being only with these principles themselves. The principles of practical reason, in other words, can be said to be built into human agency and to shape it from within.

These remarks bear directly on the foundation of practical reason granted by the constitutivist argument just introduced. For one thing, the argument claims that the principles of practical reason are binding on us, since they are ultimately rooted in the essential structure and unity-human agency — which they themselves contribute to constitute. For another thing, the argument shows that the principles of practical reason are necessary, as we cannot lose that unity without thereby shedding our agency, thus failing to act as human agents. The validity of practical reason should, then, be regarded as independent from an individual agent's subjective features: it derives from a trait that has been argued to be constitutive of human agency in general. This is to say that the binding quality of the principles of practical reason depends on the responsiveness to reasons, as this can be found in human agents, which responsiveness, being rooted in the general capacity for self-reflection, describes any human agent. Therefore, the validity of the principles of practical reason lies ultimately in a certain basic, non-contingent capacity of acting subjects, capacity distinctive to human agency and so attributable to all human agents indiscriminately.

As one may gather from this restatement, the constitutivist foundation of practical reason introduced here shares with Alexy's foundation a transcendental component and a distinctively Kantian quality. The affinity between the constitutivist foundation argued for here and Alexy's discourse-theoretical one provides support for the claim that the constitutivist claim can be used to make up for the shortcomings of the discourse-theoretical foundation (that is, for Alexy's failure to establish a genuine necessity of practical reason) so much so that we can actually replace Alexy's argument with the constitutivist one, just by 
plugging in the new set of premises and conclusions (in place of the old) while retaining the rest of the picture unaltered.

To further elaborate on this point, I claimed earlier that the necessary starting point in the argument theorized within the discourse-theoretical approach (our making assertions) presupposes a necessary condition (our compliance with the basic principles of practical reason) that turns out to be not so necessary, for we can disregard these principles and still account ourselves to be participants in a discursive setting framed by the very principles we are disregarding. Hence Alexy's weak transcendental-pragmatic foundation of practical reason, where practical reason is found to be necessary, but only selectively so, depending on contingent circumstances and, ultimately, on our willingness to engage argumentation and discourse. By contrast, the constitutivist argument introduced in this section shows that there is never an occasion on which we can disregard or bracket off the principles of practical reason without thereby losing our status as human agents. That is because, in the alternative foundation argued for in this section, the principles of practical reason are constitutive of our human agency: there is no agency without those principles. Therefore, there are no grounds, on a constitutivist foundation, for any conduct engaged in without regard to the principles of practical reason, since that would be a step away from the very agency that accounts for who we essentially are, thus unlike what is the case in discourse theory, as defended by Alexy, where we can contradict practical reason (the principles of discursive rationality) and still pass muster as rational-discursive agents.

The constitutivist claim just made should not be taken to mean that we can never deviate from the principles of practical reason. In the constitutivist framework, practical reason is something we can and in fact may well deviate from: we are all familiar with behaviour that cannot be made to square with anything we would recognize as practical reason. But there is an important difference between the constitutivist stance and the discourse-theoretical one: it lies in the conceptual consequences that follow from such deviation. For, as we have seen, we can be discursive participants in argumentation even while ignoring the principles of discursive engagement (no serious conceptual consequence, therefore, attaches to our disregard of practical reason); by contrast, we cannot be agents in the constitutivist sense while ignoring the principles of practical reason, namely, the principles that make us agents to begin with. The reason why we cannot - or why we stand to lose our agency in consequence of our disregard of the principles of practical reason-is precisely that those principles are constitutive of our agency, rather than something that makes us better or worse agents depending on the degree to which we comply. 
The same idea can be restated in terms of agency and action by noting that no agent can be an agent who does not engage in principled conduct, or action proper, and there is no way for us to engage in principled conduct except as unified agents behaving in accordance with the principles of practical reason. What explains this watertight construction is the mutually entailing relation that constitutivism understands there to obtain between human agency and principled conduct, whereby our agency entails principled conduct (as a consequence), just as principled conduct entails agency (as a precondition). It is therefore an unbreakable bond that obtains between agency and principled conduct, a direct link established through the principles of practical reason as used in the transcendental-constitutive argument outlined above. This makes the principles of practical reason an essential, necessary part of our agency, thereby making it impossible for us to step outside the boundaries they mark without thereby ceasing to be the kinds of persons the theory envisions as its basic units of agency. This also poses an obstacle for anyone expressing scepticism that the principles of practical reason are necessary, arguing that these principles are only loosely connected to action. Indeed, it is only from within practical reason that we can call its principles into doubt - that is, only as agents can we call practical reason into doubt — and yet in denying the validity of practical reason, the sceptic must deny her own agency, that is, she must deny the very position from which she is expressing her scepticism, which is contradictory, for it amounts to denying the preconditions of the denial itself. ${ }^{43}$ And herein lies the greater power of the foundation outlined here and its greater ability to withstand sceptical criticism: this is owed to the reliance of the foundational argument on the idea of constitutive necessity. For, as we have seen, to constitute something is to define and bring it into being as the kind of thing it is, in such a way that we can recognize it as what it is rather than as something else. ${ }^{44}$

The constitutive necessity of the principles of practical reason is conditional rather than absolute: if we want to consider ourselves agents, we will have to follow the principles of practical reason, failing which we would exit the realm of agency. Thus, as much as we can have such loss of agency, meaning that the necessity involved is not so stringent, it is nonetheless a necessity that we are looking at. For it does not allow any slippage between practical reason and agency: there is no scenario that on this construction can be envisioned

\footnotetext{
${ }^{43}$ Korsgaard concludes on this basis that "constitutive standards meet sceptical challenges to their authority with ease," and that there is "no further room for doubting" their normative force. Christine Korsgaard, SelfConstitution (Oxford: Oxford University Press, 2009), p. 29.

${ }^{44}$ As Korsgaard puts it, what it means for a standard or principle to be constitutive of something-here our agency and the activity we perform as agents - is that "if you are not guided by the principle, you are not performing the activity at all". Christine Korsgaard, Self-Constitution (Oxford: Oxford University Press, 2009), 28.
} 
where we might neglect to adhere to practical reason and yet still retain our status as agents or, in Alexy's vocabulary, our ability to participate in the most basic form of life. This is something that constitutivism can do without appealing to any logical, or conceptual, kind of necessity in showing practical reason to be necessary. Indeed, as Alexy has correctly argued in his recent work, there is no logical contradiction involved in disregarding what practical reason demands, nor is such behaviour conceptually impossible, as is evidenced by the less than extraordinary examples of noncompliance we can observe as a matter of fact. This does not mean, however, that we have to back away from the idea of necessity altogether, by constructing practical reason as an activity ultimately grounded in an existential decision, that is, in a commitment to our status as discursive creatures. While such a commitment may not be entirely subjective, it does diminish the role that reason plays in its own foundation, and there are other options open to us.

One such option, as we have seen-once we discard the logical foundation and the conceptual foundation, on the one hand, and the foundation that ultimately relies on an existential decision, on the other-consists in anchoring practical reason to what is constitutive of us. Constitutive necessity is not as strong as logical necessity or conceptual necessity, since it allows for the possibility of deviance: we are not logically or conceptually compelled to adhere to what is constitutive of us, and, because of this, it is a practical possibility for us to disregard the principles of practical reason. It is a practical possibility, however, that brings with it the consequence of removing us from the sphere of agency, or of effacing our identity as agents, albeit momentarily, in that we would no longer be distinctively recognized as the kinds of creatures which those principles make us by virtue of our espousing them. The reason is that such principles constitute our agency, which would not exist but for those very principles. And therein lies the kernel of constitutive necessity.

\section{Conclusion}

In this paper I critically introduced one conception of law as practical reason-Alexy'sbefore considering what practical reason rests on, or what its foundation is. Alexy, I claimed, uses to this end a transcendental-pragmatic argument whose starting point is the practice of making assertions. He argues, more specifically, that we must all make assertions if we are to be recognized as participants in discourse, and that one's participation in discourse presupposes certain principles - the principles of practical reason-failing to observe which we could not make assertions to begin with. These principles can thus be thought to be necessary. Alexy, however, gives way to sceptical doubts when he concedes that we could 
choose not to make assertions, thereby disregarding the principles of practical reason, and yet still be considered participants in that most basic form of interactive human life, which is discourse. This concession, I argued, so weakens his foundational argument as to ultimately make our reliance on practical reason a matter of personal choice.

This is too subjective a basis on which to rest practical reason, showing it to be an option rather than a necessity. For this reason I sought to replace Alexy's foundation by drawing on the constitutivist literature in which the idea of action is brought in to structure the relationship between practical reason and agency. Action, on this framework, is what we engage in as agents capable of taking a plurality of incentives and working them into a coherent line of conduct informed by the principles of practical reason. Like the speech act of making assertions, its replacement (action) is shaped by practical reason, but unlike our assertion-making, action is not something we can turn away from and still hold on to our status as human agents. Action is thus necessary in the sense that without it we could no longer be regarded as participants in that most basic form of human life. To the extent that action can be constructed as necessary (in the sense just outlined) so can the underlying principles of practical reason (the grounds of action). What makes these principles necessary is, more specifically, their role in constituting our human agency. In the constitutive foundation of practical reason, then, the principles of practical reason constitute our agency in such a way that we could no longer perform the distinctively human type of action if we should fail to use those principles in guiding our conduct. In this constitutive necessitywhereby any failure to act in keeping with the principles of practical reason would mean we are no longer capable of engaging in genuine action - there is no longer any place where a sceptical challenge might be injected alleging a loose relation between practical reason and agency, a relation in which we could ignore the demands of practical reason without thereby forsaking our agency.

As the overall discussion makes sufficiently clear, my intent here was not to either dismantle Alexy's theory or, more generally, to call into question and criticize the conception of law as practical reason, but rather to fortify them. The aim, more to the point, was to make the conception of law as practical reason, especially in its Kantian variant, more resistant to sceptical objections. These objections, concerned with the foundation of practical reason as they are, reveal what appears to be a potentially significant weakness in any conception of law as practical reason: the lack of a demonstration of the very possibility of practical reason. Accordingly, anyone who considers the conception of law as practical reason a valuable development in legal philosophy needs to address the sceptical concerns about the possibility 
of practical reason and its foundation. For, only as long as those concerns are successfully addressed, as I have attempted to do here, it is possible to regard the conception of law as practical reason as a vantage point from which to thoroughly analyse legal systems and tackle the main problems connected with their existence as well as to rely on such a conception to gain a deep understanding of legal practice. 